Check for updates

Cite this: Mater. Adv., 2022, 3, 318

Received 29th April 2021,

Accepted 24th October 2021

DOI: $10.1039 / \mathrm{d} 1 \mathrm{ma} 00388 \mathrm{~g}$

rsc.li/materials-advances

\section{Nanodiamond-induced modifications of Eu-doped phosphate glasses toward photonic applications: A synergistic physico-chemical approach}

\begin{abstract}
Mariana Sendova (D) a and José A. Jiménez (D) *b
Phosphate glasses were melted with fixed $\mathrm{Eu}_{2} \mathrm{O}_{3}$ content and varying amounts of nanodiamond (ND) powder seeking to obtain insights into the physico-chemical aspects underpinning optical properties while tuning the light-emitting properties towards photonic applications. A synergistic quantitative study incorporating X-ray diffraction, optical transmission, photoluminescence (PL) spectroscopy, Raman scattering, and differential scanning calorimetry (DSC) was carried out. The emitted light color was characterized via its $\mathrm{CIE}$ coordinates. The data from various techniques were correlated and discussed in the framework of energy band theory, along with the carbon-induced $\mathrm{Eu}^{3+} \rightarrow \mathrm{Eu}^{2+}$ reduction concomitant with non-bridging oxygen bond modifications. The optical band gap is calculated from the transmission spectra via Tauc plots to narrow from $4.1 \mathrm{eV}$ to $3.3 \mathrm{eV}$ with increasing carbon concentration from ND ( $\left.C_{N D} \sim 0.14-1.4 \mathrm{~mol} \%\right)$. The optical band gap values appear proportional to the integral intensities of the Raman-active bands of the glass. The $E u^{2+}$ absorption band of the $4 f^{7} \rightarrow 4 f^{6} 5 d$ transition is deduced from the absorption spectra of the glass and utilized to explain the optical band gap narrowing concentration-trend with $5 d$ levels introduced below the conduction band edge. A novel method for quantifying the PL emission spectra is suggested and correlated to the $C_{N D}$ concentration in the melt and to the optical band gap. Further, DSC was used to corroborate the data with the Raman and optical studies. The study contributes to the fundamental understanding and design of tunable light-emitting Eu-doped phosphate glasses for photonic applications.
\end{abstract}

\section{Introduction}

The remarkable physical properties of nanoscale diamond particles, i.e. nanodiamond (ND), have prompted investigations regarding their potential utilization for a wide variety of applications, ranging from biotechnology to integration in photonic devices. ${ }^{1-8}$ The exceptional mechanical and optical properties coupled to the high surface areas intrinsic to nanoscale materials are some of the key characteristics facilitating various technologies. ${ }^{2,5}$ On the other hand, ND also holds high chemical stability (low oxidative stress), exhibiting high resistance to harsh environments. This makes ND particularly attractive for applications in high-temperature chemistry wherein a durable form of carbon is preferred over other allotropes such as multiwall carbon nanotubes (MWCNTs) or graphite. In this context, it has been recently reported by the authors ${ }^{9,10}$ that ND powder efficiently allows for the synthesis of UV-transparent phosphate glasses in association with $\mathrm{P}-\mathrm{O}-\mathrm{C}$ bond formation effectively

\footnotetext{
${ }^{a}$ Optical Spectroscopy \& Nano-Materials Lab, New College of Florida, Sarasota, FL 34243, USA. E-mail: ijimenezlugo@augusta.edu

${ }^{b}$ Department of Chemistry \& Physics, Augusta University, Augusta, GA 30904, USA
}

increasing the covalent nature (decreasing the optical basicity) of the matrix. The carbon loadings with ND (up to $0.1 \mathrm{wt} \%)^{9}$ were found to be much lower than the concentrations used for co-doped glasses melted with MWCNTs $(0.6 \mathrm{wt} \%)^{11}$ or graphite $(0.8 \mathrm{wt} \%){ }^{12}$ Further, the chemical reductant role of the carbon provided in the form of $\mathrm{ND}\left(\mathrm{C}_{\mathrm{ND}}\right)$ facilitated the $\mathrm{Cu}^{2+} \rightarrow \mathrm{Cu}^{+} \rightarrow$ $\mathrm{Cu}^{0}$ valence states changes in copper leading to an efficient plasmonic transformation to $\mathrm{Cu}$ nanocomposite glasses. ${ }^{9}$ Expanding on the chemical/reactant role of $\mathrm{C}_{\mathrm{ND}}$ source in the melt, the present work was carried out on the synthesis of $\mathrm{C}_{\mathrm{ND}}$ and $\mathrm{Eu}_{2} \mathrm{O}_{3}$ co-doped light-emitting glasses stimulating the conversion of red-emitting $\mathrm{Eu}^{3+}$ to blue-emitting $\mathrm{Eu}^{2+}$ ions. Hence, we herein report on the results of a multifaceted systematic physico-chemical investigation wherein Eu-doped binary barium-phosphate glasses were prepared by melting with a fixed amount of $\mathrm{Eu}_{2} \mathrm{O}_{3}$ and increasing contents of ND powder in the melt. Spectroscopic and calorimetric characterizations were then performed seeking to understand the composition-structureproperty relation in the $\mathrm{C}_{\mathrm{ND}} / \mathrm{Eu}_{2} \mathrm{O}_{3}$ co-doped phosphate glasses. Insights into the connection amongst optical, structural, and thermal properties were obtained by detailed analyses via optical transmission, photoluminescence (PL) spectroscopy, Raman 
spectroscopy, and differential scanning calorimetry (DSC). In addition, a novel method for quantifying emission spectra is herein proposed which was correlated to the $\mathrm{C}_{\mathrm{ND}}$ concentration and optical band gap energies assessed. The present work indicating that emission with broad tunability was achieved due to variation in the $\mathrm{C}_{\mathrm{ND}}$ concentration may appeal to material developments in photonics.

\section{Experimental}

\subsection{Material synthesis}

The glasses were prepared with a 50BaO:50 $\mathrm{P}_{2} \mathrm{O}_{5}$ (mol\%) composition from high purity Alfa Aesar chemicals $\left(\mathrm{P}_{2} \mathrm{O}_{5}\right.$, $\geq 98 \%$ and $\mathrm{BaCO}_{3}, 99.8 \%$ ) by the melt-quenching technique. ${ }^{9}$ Batch materials were weighed, thoroughly mixed and melted in porcelain crucibles at $1150{ }^{\circ} \mathrm{C}$ between 15 and 20 min under normal atmospheric conditions and quenched in a steel mold. Annealing to remove mechanical/thermal stress was done at $420{ }^{\circ} \mathrm{C}$ for 3 hours. Europium oxide was added as $\mathrm{Eu}_{2} \mathrm{O}_{3}$ (Alfa Aesar, 99.99\%) at the fixed amount of $1 \mathrm{~mol} \%$ relative to $\mathrm{P}_{2} \mathrm{O}_{5}$ in all glasses, prepared with different amounts of ND powder (Sigma-Aldrich, $<10 \mathrm{~nm}, \geq 97 \%$ ) added as part of the batch materials as $0.010,0.040,0.070$ and $0.10 \mathrm{wt} \%$. The glasses presented colorless and transparent appearance [photograph of some samples shown in Fig. 2(a)]. Glasses were cut and polished to produce slabs for optical measurements with final thicknesses of about $1.0 \mathrm{~mm}$. Sample codes and translated nominal molar compositions for the glasses of this study are summarized in Table 1.

\subsection{Measurements}

X-Ray diffraction (XRD) measurements were performed on the glasses to confirm the overall amorphous structure with a Rigaku MiniFlex benchtop X-ray diffractometer with $\mathrm{Cu}-\mathrm{K} \alpha$ radiation $(\lambda=1.5406 \AA)$ over the $10^{\circ} \leq 2 \theta \leq 80^{\circ}$ angular range.

The UV/Vis optical transmission measurements were performed on the glass slabs fixed on a custom-made sample holder with an Agilent Cary 300 series double-beam spectrophotometer; the reference during the measurements was always air.

The PL data was acquired with a Horiba-PTI QM-8075-21 spectrofluorometer equipped with a continuous illumination Xe lamp. Corrected spectra were obtained under the steadystate conditions through the FelixGX software by utilizing instrument calibration files provided by the manufacturer to perform the spectral corrections. The step size used for spectral

Table 1 Glass codes, matrix composition and concentrations of $\mathrm{Eu}_{2} \mathrm{O}_{3}$ and carbon $\left(\mathrm{C}_{\mathrm{ND}}\right)$ added in the form of nanodiamond powder (mol\%)

\begin{tabular}{lllll}
\hline Glass & $\mathrm{BaO}$ & $\mathrm{P}_{2} \mathrm{O}_{5}$ & $\mathrm{Eu}_{2} \mathrm{O}_{3}$ & $\mathrm{C}_{\mathrm{ND}}$ \\
\hline Eu & 49.750 & 49.750 & 0.500 & - \\
EuND1 & 49.680 & 49.680 & 0.497 & 0.142 \\
EuND2 & 49.470 & 49.470 & 0.495 & 0.566 \\
EuND3 & 49.260 & 49.260 & 0.493 & 0.986 \\
EuND4 & 49.053 & 49.053 & 0.491 & 1.403
\end{tabular}

acquisitions was $1 \mathrm{~nm}$. All PL measurements were recorded with samples mounted in a solid sample holder with attention given to sample position and keeping conditions constant during experiments.

Raman spectra were acquired using a Leica DMLP microscope coupled to a Raman system from Kaiser Optical Systems Inc. RamanRxn $1^{\mathrm{TM}}$ analyzer incorporates a thermoelectricallycooled charge-coupled device detector for maximum sensitivity, Invictus $^{\mathrm{TM}}$ near-IR semiconductor laser with wavelength of $785 \mathrm{~nm}$ to minimize the PL from $\mathrm{Eu}^{3+}$ ions. The spectrometer has a holographic grating to provide fast simultaneous full spectral collection of Raman data. The spectral resolution of the Raman system is $5 \mathrm{~cm}^{-1}$. All spectroscopy measurements were carried out at room temperature.

The glass transition temperature, $T_{\mathrm{g}}$, the activation energy of the glass transition regime, $E_{T_{g}}$ and the liquid fragility factor, $m$, with the associated uncertainties, were determined from a set of measurements carried out with a TA Instruments Q20 differential scanning calorimeter following the constant cooling rate cycles developed in our group. ${ }^{13}$ OriginPro and GRAMS spectroscopy software were used for data analysis.

\section{Results and discussion}

Presented in Fig. 1 are the results from the XRD characterization performed on the Eu and EuND1-4 glasses synthesized. The inset shows the diffractogram obtained for the ND powder used as raw material for which the characteristic (111) and (220) diffraction peaks of diamond NPs are observed. ${ }^{14}$ The broad diffuse scattering at lower angles typical of long-range structural disorder is noticeable for all five glasses. This, along with the fact that there are no sharp peaks detected, support the overall amorphous nature of the glasses. The authors suggest that the

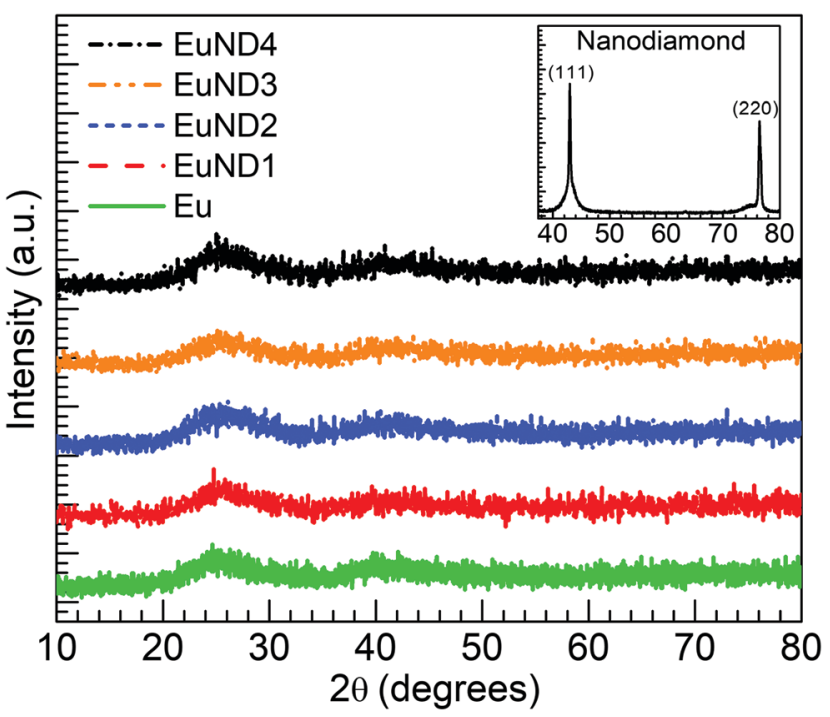

Fig. 1 XRD data confirming the amorphous nature of the Eu and EuND14 glasses. The inset shows the diffractogram obtained for the ND powder used as raw material for which the characteristic (111) and (220) diffraction peaks are observed. 
ND powder serves as an efficient carbon source due to its favorable etching rate. It was reported that at $600{ }^{\circ} \mathrm{C}$ the etching rate is $10 \mathrm{~nm} \mathrm{~h}{ }^{-1} \cdot{ }^{15}$ Given the melting temperature/time $\left(1150{ }^{\circ} \mathrm{C} / \geq 15 \mathrm{~min}\right)$ and the starting ND particle size, $<10 \mathrm{~nm}$, it is highly unlikely that any ND particles have survived in the final glass matrix. The XRD data in Fig. 1 supports this hypothesis. The presented XRD spectra have no indication of actual nanodiamond structures surviving in the final glass.

Fig. 2(a) shows the optical transmission spectra obtained for the various glasses under consideration. The Eu glass exhibits the dip in the transmission spectrum around $393 \mathrm{~nm}$ due to ${ }^{7} \mathrm{~F}_{0} \rightarrow{ }^{5} \mathrm{~L}_{6}$ transition of $\mathrm{Eu}^{3+}$ ions, ${ }^{16,17}$ while the host absorption edge characterizes the decreased transmission toward shorter wavelengths. ${ }^{9}$ It is observed for the EuND1 glass that a decreased transmission developed around $320 \mathrm{~nm}$ while the glass appears to have the transmission edge shifted towards shorter wavelengths. A similar result is observed for the EuND2 glass, however with more pronounced reduction in the transmission around $320 \mathrm{~nm}$. Thereafter, the increase in the ND contents results in a significantly decreased transmission for the EuND3 and EuND4 glasses. Such lowering in the transmission around $320 \mathrm{~nm}$ is attributed to the $4 \mathrm{f}^{7}$ to $4 \mathrm{f}^{6} 5 \mathrm{~d}$ inter-configurational transitions in $\mathrm{Eu}^{2+}$ ions which are quite intense due to the allowed character for the light absorption process. ${ }^{18,19}$ The results resemble the recently reported for the glasses melted with $\mathrm{Eu}_{2} \mathrm{O}_{3}$ and MWCNTs in our group, ${ }^{20}$ however the current spectra are achieved with ten times lower carbon $\left(\mathrm{C}_{\mathrm{ND}}\right)$ loadings. Similar evolution in transmission spectra were also reported by Tratsiak et al. ${ }^{16}$ and Liang et al. ${ }^{19}$ following the conversion from $\mathrm{Eu}^{3+}$ to $\mathrm{Eu}^{2+}$ in silicate and borophosphate glasses, respectively. The development of the transmission in Fig. 2(a) decreasing with the increase in ND content is consistent with an increase in $\mathrm{Eu}^{2+}$ concentration up to the EuND4 glass. However, the $\mathrm{Eu}^{3+}$ feature around $393 \mathrm{~nm}$ is concurrently seen in all glasses. It indicates the co-existence of both oxidation states of europium as similarly observed in the work reported in ref. 20, and further reflected in the results from PL measurements (vide infra). Hence, in analogy to recent work evaluating the role of MWCNTs, ${ }^{20}$ the partial $\mathrm{Eu}^{3+} \rightarrow \mathrm{Eu}^{2+}$ reduction occurring in the melt via carbon provided by $\mathrm{ND}\left(\mathrm{C}_{\mathrm{ND}}\right)$ may be represented as

$$
\begin{aligned}
& \mathrm{Eu}_{2} \mathrm{O}_{3}+\mathrm{C}_{\mathrm{ND}} \rightarrow 2 \mathrm{EuO}+\mathrm{CO} \\
& \mathrm{Eu}_{2} \mathrm{O}_{3}+\mathrm{CO} \rightarrow 2 \mathrm{EuO}+\mathrm{CO}_{2}
\end{aligned}
$$

While the ND would be promoting the reduction of $\mathrm{Eu}_{2} \mathrm{O}_{3}$, some losses are expected due to oxidation in air. However, these are suggested to be less than the losses with MWCNTs derived carbon doping ${ }^{20}$ in connection with the high chemical stability of ND and resistance to oxidation.

From the transmission spectra, Fig. 2(a), the absorption spectra were calculated, and analyzed. Then, the optical band gap of the glasses is assessed, and its $\mathrm{C}_{\mathrm{ND}}$ concentration trend is discussed within the energy band theory applied to glasses. The optical absorption coefficient, $\alpha$, exhibits a logarithmic dependence with the optical path length, $d$. According to the (a)

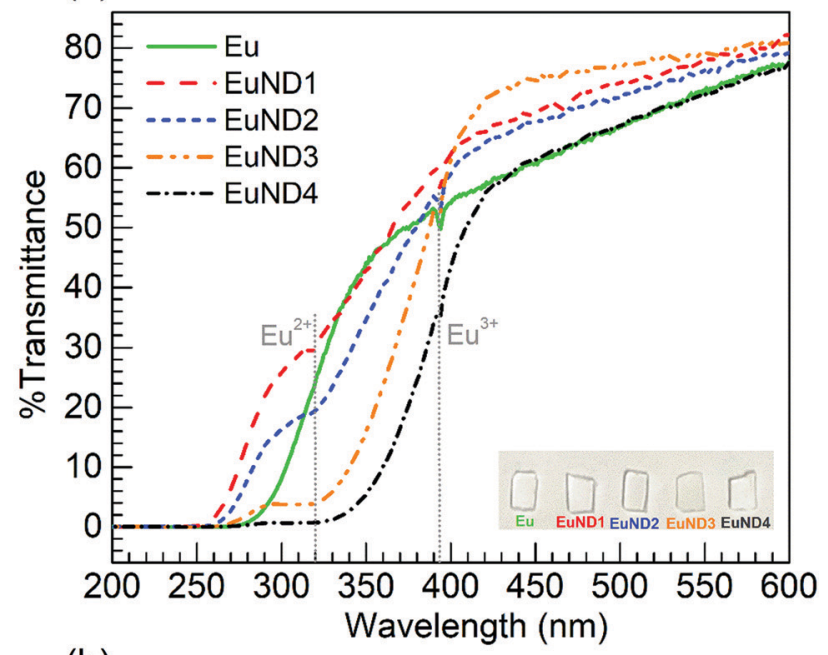

(b)

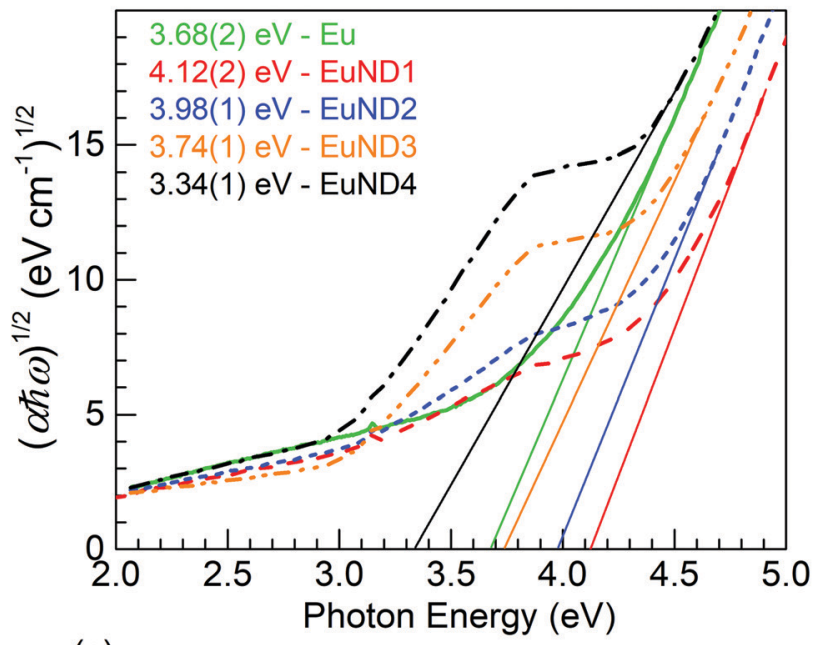

(c)

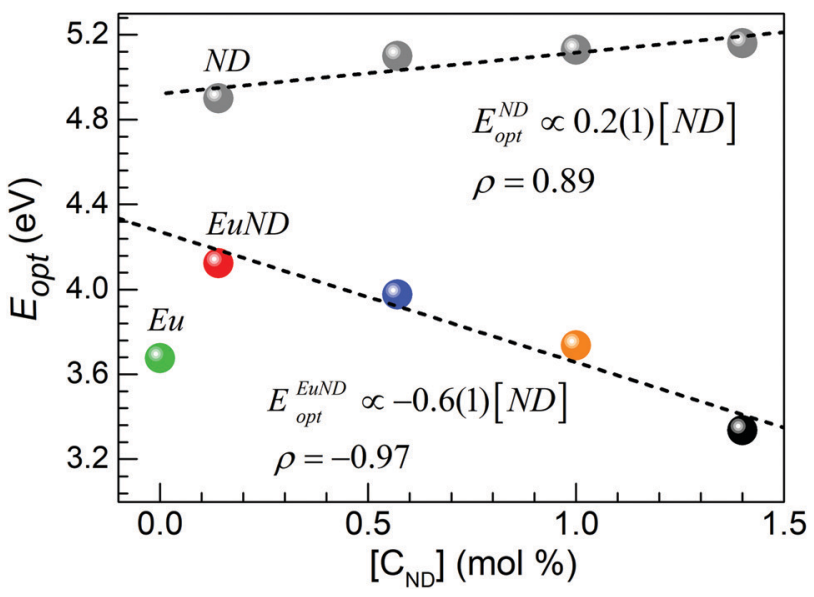

Fig. 2 (a) Transmission spectra of the Eu and EuND1-4 glasses (the inset is a photograph of some glass samples on white background). (b) Corresponding Tauc plots with optical band gap values listed. (c) Optical band gaps comparison between two sets of barium phosphate glasses, without Eu, i.e. labeled $\mathrm{ND}^{9}$ and with Eu doping (EuND glasses in this study) correlated to the added $\mathrm{C}_{\mathrm{ND}}$ concentration (mol\%) in the melt. 
Bouguer-Lambert-Beer absorption law as

$$
\alpha=\frac{1}{d} \ln \left(\frac{100}{T}\right)
$$

where $T$, is the transmission (\%). In this study, $\alpha$, is assessed numerically from the transmission spectra in Fig. 2(a) (sample thickness, $d=0.1 \mathrm{~cm}$ ), while the wavelength is converted to photon energy, $\hbar \omega$. As a next step, plots of $(\alpha \hbar \omega)^{1 / 2} v s$. $\hbar \omega$ (i.e. Tauc plots), were created, ${ }^{21}$ which are presented in Fig. 2(b). However, to standardize the numerical analysis a rigorous numerical algorithm is proposed for assessing the optical band gap value and the uncertainty of the single measurement. We propose the steepest section of the Tauc plot, Fig. 2(b), to be determined by taking numerically, the first order derivative $\frac{\mathrm{d}(\alpha \hbar \omega)^{1 / 2}}{\mathrm{~d}(\hbar \omega)}$ and finding the position, $\hbar \omega_{\max }$, from $\frac{\mathrm{d}(\alpha \hbar \omega)^{1 / 2}}{\mathrm{~d}(\hbar \omega)}=0 .{ }^{10}$ After establishing the steepest section of the Tauc plot, 5-10 points to the left of the maximum, $\hbar \omega \leq \hbar \omega_{\max }$, are employed for a linear regression. The correlation coefficient (Pearson's $\rho$ ) is estimated to vary between 0.99998 (for 5 pts regression) and 0.998 (for 10 pts regression). Extrapolating the linear regression to, yields the optical band gap of the glass (Tauc band gap, $E_{\text {opt }}$ ). The optical band gap values are listed in the inset of Fig. 2(b), color coded according to the legend. The uncertainty of the single measurement is evaluated from the linear regression analysis, and its value is presented in parentheses, pertaining to the last reported decimal. The reported band gap uncertainty is limited only to the regression analysis. Further on, utilizing the assessed $E_{\text {opt }}$ values, it was established that a strong correlation (Pearson's coefficient $\rho=-0.97$ ) exists between the optical band gap values and the ND concentration in the melt, Fig. 2(c) EuND data points, $E_{\mathrm{opt}}^{\mathrm{ND}}$. In the same figure $E_{\mathrm{opt}}^{\mathrm{ND}}$ values of a series of $\mathrm{C}_{\mathrm{ND}}$ doped barium phosphate glasses (without the Eu co-doping) are included [grey bullet points Fig. 2(c)]. The optical band gap values, $E_{\mathrm{opt}}^{\mathrm{ND}}$, were analyzed and reported in a previous study. ${ }^{9}$ As the data indicates, the $\mathrm{C}_{\mathrm{ND}}$ co-doping alone, opens the optical band gap, proportionally to the $\mathrm{C}_{\mathrm{ND}}$ concentration in the melt with rate of $\sim 0.2 \mathrm{eV} /(\mathrm{ND} \mathrm{mol} \%)$, assessed by the slope of the linear fit, presented in Fig. 2(c) (dashed fitting line to the grey data points). The $E_{\mathrm{opt}}^{\mathrm{ND}}$ widening with $\mathrm{C}_{\mathrm{ND}}$ concentration is associated with the formation of P-O-C bonds, as supported by ${ }^{31} \mathrm{P}$ NMR studies ${ }^{9,10}$ (Fig. 2 and Table 2 in ref. 9; Fig. 3 and Table 1 in ref. 10) and Raman spectroscopy results reported herein. The $\mathrm{P}-\mathrm{O}-\mathrm{C}$ bonds are suggested to promote electron localization, lowering the valence band edge thus leading to widening the optical band gap, Fig. 2(c), ND data points. Therefore structurally, the $E_{\mathrm{opt}}^{\mathrm{ND}}$ increase, might be manifested as relative decrease in nonbridging oxygen (NBO) moieties at the expense of the $\mathrm{P}-\mathrm{O}-\mathrm{C}$ bonding (vide infra). According to the perturbed ion (PI) model for calculating the band gap of ionic crystals, ${ }^{22,23}$ optical absorption arises due to electron transfer from valence band of the anion to the conduction band of the cation. The authors proposed the PI model to be extended to the phosphate glasses under consideration. ${ }^{10}$ The ionic interactions between the NBOs

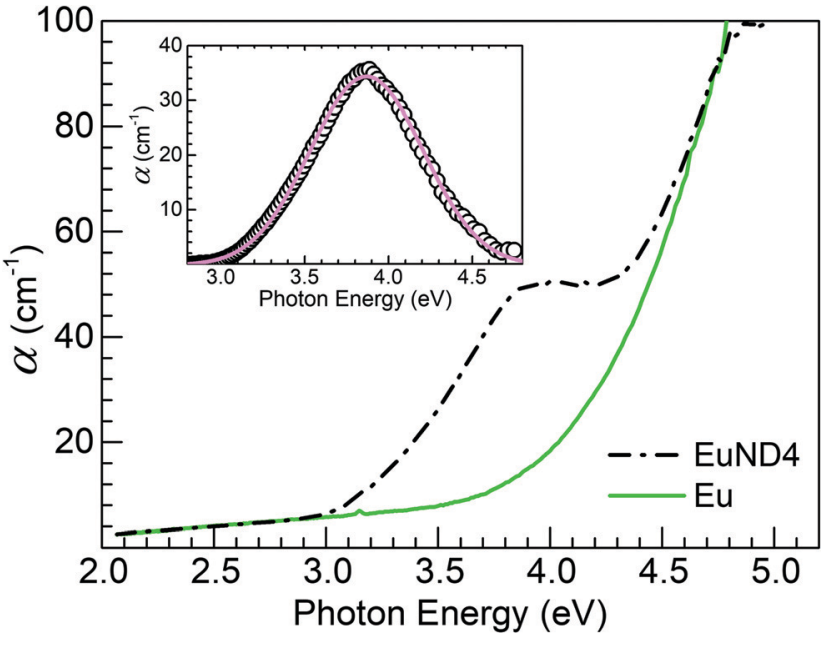

Fig. 3 Absorption spectra of the EuND4 glass along with the absorption spectrum of the Eu reference utilized for background subtraction, aimed at assessing the position of the $\mathrm{Eu}^{2+}$ absorption band. The resulting difference spectrum is plotted in the inset as the open circles (the solid line is a Gaussian fit).

of the phosphorus tetrahedral units and cationic modifiers are instrumental in shaping the width of the optical band gap. In the current study the ND glasses are additionally co-doped with $\mathrm{Eu}_{2} \mathrm{O}_{3}$. Interestingly, the europium co-doping at relatively low levels $\sim 0.5 \mathrm{~mol} \%$ turns out to exhibit profound a effect on the optical band gap width. Increasing $\mathrm{C}_{\mathrm{ND}}$ concentrations in the presence of $\mathrm{Eu}$ ion, yields strong optical band gap narrowing trend estimated at $-0.6 \mathrm{eV} /\left(\mathrm{C}_{\mathrm{ND}} \mathrm{mol} \%\right)$. The estimate is done from the linear fit to the $E_{\mathrm{opt}}^{\mathrm{NDEu}}$ values, EuND data points, Fig. 2(c). The barium phosphate glass co-doped only with $\mathrm{Eu}$ serves as a reference in this study [a green bullet point, Fig. 2(c)]. Quick comparison reveals that the $\sim 0.5 \mathrm{~mol} \%$ Eu co-doping negates the band gap broadening of $\sim 1 \mathrm{~mol} \%$ of $\mathrm{C}_{\mathrm{ND}}$ in the EuND3 glass, and the reference Eu glass has similar band gap $E_{\text {opt }} \approx 3.7 \mathrm{eV}$ in contrast to the ND glass (grey bullet point) with $E$ ${ }_{\mathrm{NDt}}^{\mathrm{ND}} \approx 5.1 \mathrm{eV}$. As indicated earlier (vide supra), the reason for such dramatic decrease of the band gap in the presence of europium ions is the reductant role played by the carbon source. $\mathrm{C}_{\mathrm{ND}}$ partially reduces $\mathrm{Eu}^{3+} \rightarrow \mathrm{Eu}^{2+}$ in the melt which also manifests through the luminescent properties presented below. The optical band gap of the EuND glass series is thus affected by the f-d optical transitions of the $\mathrm{Eu}^{2+}$ ions, namely $4 \mathrm{f}^{7}$ to the crystal field split $4 f^{6} 5 d$ level $\left(e_{g}\right.$ and $\left.t_{2 g}\right){ }^{18,19}$

In an attempt to quantify the decreased transmission around $320 \mathrm{~nm}$, Fig. 2(a), the Eu glass reference absorption spectrum was subtracted from the absorption spectrum of the EuND4 glass. Fig. 3 summarizes the analysis process. A Gaussian absorption band with peak at $3.9 \mathrm{eV}(318 \mathrm{~nm})$ and full-width at half-maximum (FWHM) of $0.8 \mathrm{eV}$ is revealed after the spectral subtraction. The absorption band peak position agrees with the lower of the two $\mathrm{Eu}^{2+}$ crystal field split $4 \mathrm{f}^{7} \rightarrow 4 \mathrm{f}^{6} 5 \mathrm{~d}$ electronic level transitions, namely e $\mathrm{e}_{\mathrm{g}}$. Nogami et al. ${ }^{18}$ reported the two absorption bands at $3.9 \mathrm{eV}\left(\mathrm{e}_{\mathrm{g}}\right)$ and $5.1 \mathrm{eV}\left(\mathrm{t}_{2 \mathrm{~g}}\right)$ in aluminosilicate glass prepared by sol-gel method. Liang et al. ${ }^{19}$ 
reported $3.7 \mathrm{eV}\left(\mathrm{e}_{\mathrm{g}}\right)$ and $4.3 \mathrm{eV}\left(\mathrm{t}_{2 \mathrm{~g}}\right)$ in co-doped borophosphate glasses. Therefore, the $\mathrm{Eu}^{2+}$ ion $5 \mathrm{~d}$ orbital, split into two components of $e_{g}$ and $t_{2 g}$ by the local crystal-field introduces two distinguishable, discrete acceptor type energy levels below the conduction band edge of the phosphate glass host. (1) The $t_{2 g}$ energy level, closer to the conduction band edge, is revealed by reduced $E_{\mathrm{Opt}}^{\mathrm{NDE}}$ values. The transition energy $4 \mathrm{f}^{7} \rightarrow 4 \mathrm{f}^{6} 5 \mathrm{~d}\left(\mathrm{t}_{2 \mathrm{~g}}\right)$ is reported to be $>4.3 \mathrm{eV}^{18,19}$ and the assessed herein, $E_{\mathrm{opt}}^{\mathrm{NDE}}$ with the lowest $\mathrm{C}_{\mathrm{ND}}$ concentration, EuND1 is 4.1(1) eV. Further increase of the concentration of the reduced europium ions leads to increased density of $5 \mathrm{~d}$ states below the edge of the conduction band, effectively further narrowing the optical band gap, Fig. 2(c) (EuND data points). (2) The electronic transitions to the lower, $\mathrm{e}_{\mathrm{g}}$ level give rise to the shoulder in the transmission (absorption) spectra, Fig. 2(a, b), Fig. 3. Therefore, there are two opposing trends in relation to the $E_{\mathrm{opt}}^{\mathrm{NDE}}$ evolution with increasing $\mathrm{C}_{\mathrm{ND}}$ : (i) lowering the valence band edge due to the increased covalent character of the glass former, via promotion of $\mathrm{P}-\mathrm{O}-\mathrm{C}$ bonds; and (ii) concomitant introduction of $\mathrm{Eu}^{2+} 4 \mathrm{f}^{6} 5 \mathrm{~d}$ levels effectively lowering the conduction band edge. It appears that the second effect is dominant. The ratio between the concentration rates of the two opposing processes can be assessed from the ratio of the corresponding linear slopes, Fig. 2(c) inset: $(-0.6-0.2) / 0.2=-4$. Therefore, the data suggests the reducing role of $\mathrm{C}_{\mathrm{ND}}$ is a four-fold more potent mechanism for altering the optical band gap of the glass than the $\mathrm{P}-\mathrm{O}-\mathrm{C}$ bond formation. The former effect will be examined by PL spectroscopy, while the latter will be further investigated by Raman spectroscopy below.

Shown in Fig. 4 are emission spectra obtained for the glasses under the excitation wavelength of $320 \mathrm{~nm}$ in accord with the $\mathrm{Eu}^{2+}$ absorption feature in Fig. 3. The presence of $\mathrm{Eu}^{2+}$ is evidenced for the EuND1-4 glasses by the broad $5 \mathrm{~d} \rightarrow 4 \mathrm{f}$ emission band ${ }^{16,18,24}$ with maximum around $450 \mathrm{~nm}$ which is absent for the Eu glass. However, a saturation in the blue

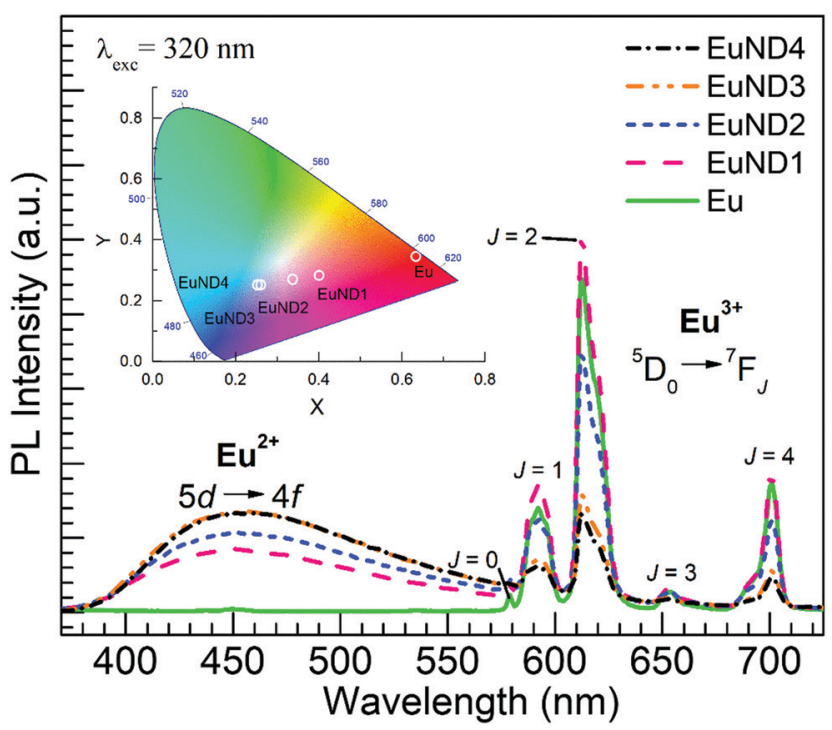

Fig. 4 Emission spectra obtained under excitation at $320 \mathrm{~nm}$ for the Eu and EuND1-4 glasses. The color coordinates of the emission are presented in the CIE chromaticity diagram, inset. emission from $\mathrm{Eu}^{2+}$ is observed after $1.0 \mathrm{~mol} \% \mathrm{ND}$. It turns out that the EuND4 glass which presented the lowest transmission in Fig. 2 thus pointing to the highest $\mathrm{Eu}^{2+}$ content, does not show greater intensity in the band emission than the EuND3 glass. In addition, the characteristic emission of $\mathrm{Eu}^{3+}$ ions due to the ${ }^{5} \mathrm{D}_{0}$ $\rightarrow{ }^{7} \mathrm{~F}_{J}(J=0,1,2,3,4)$ transitions $^{18,24}$ is seen in the Eu and the EuND1-4 glasses. This harmonizes with the coexistence of $\mathrm{Eu}^{3+}$ ions already indicated by the transmission spectra (Fig. 2) since $320 \mathrm{~nm}$ is resonant with exciting the ${ }^{7} \mathrm{~F}_{0} \rightarrow{ }^{5} \mathrm{H}_{4}$ transition in $\mathrm{Eu}^{3+} \cdot{ }^{17,25}$ Thus $\mathrm{Eu}^{2+} / \mathrm{Eu}^{3+}$ co-doping facilitated by $\mathrm{C}_{\mathrm{ND}}$ introduction in the melt, yields tunable colored emission with color coordinates presented in the CIE diagram, Fig. 4 inset. It is worth noting in Fig. 4 that the emission intensities for the transitions in $\mathrm{Eu}^{3+}$ ions are highest for the EuND1 glass, followed by the Eu reference. The order of the intensity for the most prominent ${ }^{5} \mathrm{D}_{0}$ $\rightarrow{ }^{7} \mathrm{~F}_{2}$ transition around $613 \mathrm{~nm}$ is as follows: EuND1 (highest) $>$ Eu $>$ EuND2 $>$ EuND3 $>$ EuND4 (lowest). The $613 \mathrm{~nm}$ peak intensity increases by about $13 \%$ for the EuND1 glass relative to the $\mathrm{Eu}$ reference. This is an interesting result given that the EuND1 having less $\mathrm{Eu}^{3+}$ content than the $\mathrm{Eu}$ reference would intuitively be expected to have a lower $\mathrm{Eu}^{3+}$ emission intensity. A similar result was recently reported for a glass melted with $0.3 \mathrm{wt} \%$ MWCNT together with $\mathrm{Eu}_{2} \mathrm{O}_{3}$ where the PL intensity for the $613 \mathrm{~nm}$ peak increased relative to the $\mathrm{Eu}$ reference. ${ }^{20}$ In addition, a similar result was observed by Nogami et al. ${ }^{18}$ who first performed the $\mathrm{Eu}^{3+} \rightarrow \mathrm{Eu}^{2+}$ reduction in $\mathrm{Al}_{2} \mathrm{O}_{3}-\mathrm{SiO}_{2}$ solgel glass under $20 \% \mathrm{H}_{2}-80 \% \mathrm{~N}_{2}$ atmosphere, followed by heating in air at $800{ }^{\circ} \mathrm{C}$ which led to partial $\mathrm{Eu}^{2+} \rightarrow \mathrm{Eu}^{3+}$ re-oxidation. It was reported that the luminescence intensity for the $\mathrm{Eu}^{3+}$ ions increased after the heating in air approaching a value larger than 1.5 times the intensity before the $20 \% \mathrm{H}_{2}-80 \% \mathrm{~N}_{2}$ treatment. ${ }^{18}$ It was concluded that such enhanced $\mathrm{Eu}^{3+} \mathrm{PL}$ was due to the $\mathrm{Eu}^{2+} \rightarrow$ $\mathrm{Eu}^{3+}$ energy transfer process. ${ }^{18}$ Such energy transfer similarly acknowledged by other researchers, ${ }^{16,24,26}$ seems to be manifested herein for the lowest amount of ND powder added to the EuND1 glass which showed greater $\mathrm{Eu}^{3+} \mathrm{PL}$ intensity than the Eu glass. On the other hand, the subsequent decrease in $\mathrm{Eu}^{3+}$ emission reflected for the EuND2, EuND3 and EuND4 glasses in Fig. 4 agrees with a decrease in $\mathrm{Eu}^{3+}$ concentration produced by the reducing process supported by the ND, e.g. eqn (1) and (2).

Fig. 5 shows the PL spectra obtained for the various glasses under excitation at $310 \mathrm{~nm}$ to focus on the blue emission from $\mathrm{Eu}^{2+}$, since under such excitation the emission from $\mathrm{Eu}^{3+}$ ions is minimized. The bluish character of the overall luminescence is quantified by the CIE coordinates presented in the inset of Fig. 5. The PL emission trend is clearly seen as a decrease in intensity in the order: EuND3 (highest) $\approx$ EuND4 $>$ EuND2 $>$ EuND1 > Eu (absent). Again, the trend observed in Fig. 2(a) for the transmission decreasing following the increase in ND content is not followed, as it was similarly observed for the glasses melted with MWCNTs and $\mathrm{Eu}_{2} \mathrm{O}_{3}$ as reported. ${ }^{20}$ As pointed by Tratsiak et al., ${ }^{16}$ many excitation-reabsorption processes involving $\mathrm{Eu}^{2+} \leftrightarrow \mathrm{Eu}^{2+}$ and $\mathrm{Eu}^{2+} \rightarrow \mathrm{Eu}^{3+}$ interactions may occur that can lead to a diminution of the PL intensities. Given that the $\mathrm{Eu}^{2+} \rightarrow \mathrm{Eu}^{3+}$ transfer was indicated in Fig. 4 to be significant merely for the EuND1 glass, we then consider the 


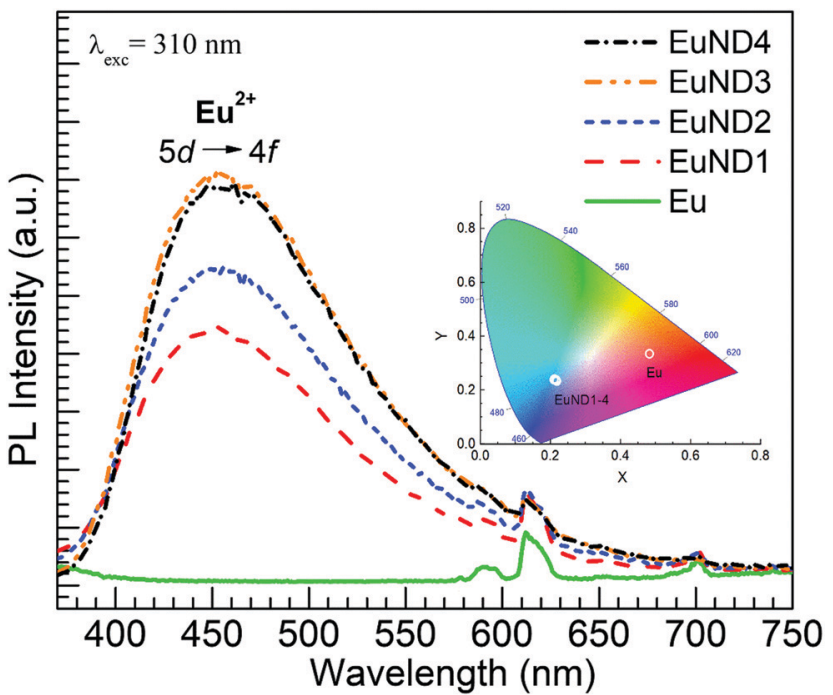

Fig. 5 Emission spectra obtained under excitation at $310 \mathrm{~nm}$ for the Eu and Eu ND1-4 glasses. The CIE diagram with the color coordinates of the emission is shown in the inset.

$\mathrm{Eu}^{2+} \leftrightarrow \mathrm{Eu}^{2+}$ interactions being at the origin of the lack of increase in the $\mathrm{Eu}^{2+} 5 \mathrm{~d} \rightarrow$ ff blue emission band after $1.0 \mathrm{~mol} \%$ ND. In other words, the well-known phenomenon of concentration quenching appears to be manifested for $\mathrm{Eu}^{2+}$ for the higher content of ND powder. In addition, a reduction in the optical band gap is suggested as contributing factor to the apparent saturation effect of the emission for EuND4 glass, as considered with the glasses melted with MWCNTs and $\mathrm{Eu}_{2} \mathrm{O}_{3} \cdot{ }^{19}$ The $E_{\text {opt }}$ of EuND4 of $\sim 3.3 \mathrm{eV}$ corresponds to a threshold wavelength of $376 \mathrm{~nm}$, indicating that the excitation beams with wavelengths of $310 \mathrm{~nm}$ and $320 \mathrm{~nm}(\sim 3.9 \mathrm{eV})$ are with decreased intensity, yielding comparatively less emission.

Further on, this study exploits the spectrally well-separated emission ranges of $\mathrm{Eu}^{2+}$ and $\mathrm{Eu}^{3+}$ under $320 \mathrm{~nm}$ excitation in

attempt to numerically assess the apparent integral ratio $\eta=$ $\frac{\left[\mathrm{Eu}^{2+}\right]}{\left[\mathrm{Eu}^{3+}\right]}$ of the emission and to correlate it to the $\mathrm{C}_{\mathrm{ND}}$ concentration in the melts $(\sim 0.14-1.0 \mathrm{~mol} \%)$. The PL spectra $(375 \mathrm{~nm}$ to $750 \mathrm{~nm}$ ) was numerically normalized by the total area, and the integral blue emission of the $\mathrm{Eu}^{2+}$ ions was evaluated by recording the fractional intensity between $375 \mathrm{~nm}$ to $575 \mathrm{~nm}$. As expected, a strong positive concentration correlation (Pearson's $\rho=0.998$ ) was revealed, Fig. 6(a). The slope of the fitted linear regression is $\sim(+0.33) \eta /\left(\mathrm{C}_{\mathrm{ND}} \mathrm{mol} \%\right)$. Thus, the assessed concentration rate of $\eta$ via the PL spectra, reflects the apparent europium ionic ratio, having in mind some possible underestimation of $\left[\mathrm{Eu}^{2+}\right]$ due to the suggested above energy transfer indicated in EuND1 sample. The EuND4 glass was omitted in this analysis, because it shows some emission saturation effects. Continuing the analysis, the assessed optical band gap, $E_{\mathrm{Opt}}^{\mathrm{NDE}}$, Fig. 2(c), was plotted against the integral PL factor $\eta$, for the EuND1-3 glasses, Fig. 6(b). A strong negative correlation (Pearson's $\rho=-0.997$ ) was revealed: an increased

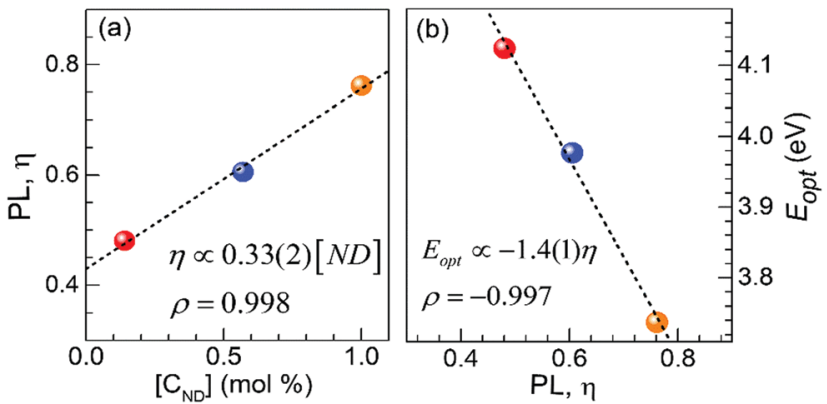

Fig. 6 (a) PL emission evaluation factor $\eta$, correlated to the molar $\mathrm{C}_{\mathrm{ND}}$ concentration in the melts for the EuND1-3 glasses. Panel (b) shows the optical band gap, $E_{\text {opt }}$ correlated with the PL emission factor. The slopes of the linear regressions and the Pearson's coefficients $(\rho)$ are listed.

PL is harmoniously correlated with the $E_{\text {opt }}$ narrowing. Therefore, the absorption studies-based hypothesis of the crucial role of the split $\mathrm{Eu}^{2+} 5 \mathrm{~d}$ levels for optical band gap narrowing in the EuND glass series is in agreement with the integral PL $\eta$ factor analysis carried out herein.

To elucidate structural changes accompanying the trends in optical properties, Raman spectroscopy is employed. The main Raman features for the studied metaphosphate glasses are detected in the range $600-1400 \mathrm{~cm}^{-1}$, Fig. 7(a). According to the Raman bands assignments, ${ }^{27}$ the investigated range is divided roughly in two sections. A broad asymmetric feature between 650 and $850 \mathrm{~cm}^{-1}$ is an envelope of continuous distribution of bridging oxygens (BOs) bond strengths of the $Q^{2}$ species, (the superscript indicates the number of BOs). Raman shifts of the $\nu_{\mathrm{s}}$ (POP) frequencies within the envelope are inversely proportional to the phosphate chain length. The second spectral section includes Raman active out-of-chain symmetrical $\nu_{\mathrm{s}}\left(\mathrm{PO}_{2}\right)$ modes of the $Q^{2}$ species. In principle, the position of the most intense Raman band, $\nu_{\mathrm{s}}\left(\mathrm{PO}_{2}\right)\left(\right.$ at $1159 \mathrm{~cm}^{-1}$ with FWHM $\sim 60 \mathrm{~cm}^{-1}$ ) is sensitive to the modifying and doping cations. The intensity of the band reflects the relative concentration of the NBOs. In the studied glass series, Fig. 7(a), no shift of the band position is detected, reflecting the lack of substantial change of the cation electrostatic field. Evidently, the overall amount of the Eu dopant and its charge changes due to the $\mathrm{C}_{\mathrm{ND}}$ co-dopant is not affecting the strength of NBOs bond. The Raman signal across the studied set of EuND glasses differs by the ratio of the integral intensities of the main bands, $I_{\mathrm{NBO}} / I_{\mathrm{BO}}$. After the background subtraction, the spectra were normalized to the maximum of the BO band, Fig. 7(a). The integral intensities are calculated by numerical integration from 639 to $821 \mathrm{~cm}^{-1}$ for the $\mathrm{BO}$ band, $I_{\mathrm{BO}}$, and from 1109 to $1198 \mathrm{~cm}^{-1}$ for the NBOs band, $I_{\mathrm{NBO}}$. EuND1 and EuND2 have $I_{\mathrm{NBO}} / I_{\mathrm{BO}}$ ratio slightly $>1$, while EuND3 and Eu ND4 have $I_{\mathrm{NBO}} / I_{\mathrm{BO}}$ ratio $<1$. The $I_{\mathrm{NBO}} / I_{\mathrm{BO}}$ ratio is plotted vs. $\mathrm{C}_{\mathrm{ND}}$ concentration, Fig. 7(b). A compelling negative correlation (Pearson's $\rho=-0.98$ ) with the $\mathrm{C}_{\mathrm{ND}}$ concentration is revealed. The slope of the linear fit (dashed black line) is listed as well. With increasing $\mathrm{C}_{\mathrm{ND}}$ concentration, the $\mathrm{NBO}$ band is suppressed due to the creation of the $\mathrm{P}-\mathrm{O}-\mathrm{C}$ bonds revealing steady decreasing trend of NBO oscillators. Apparently, the $\mathrm{C}_{\mathrm{ND}}$ co-doping lessens the number of the NBOs. The $\mathrm{P}-\mathrm{O}-\mathrm{C}$ moieties 
(a)

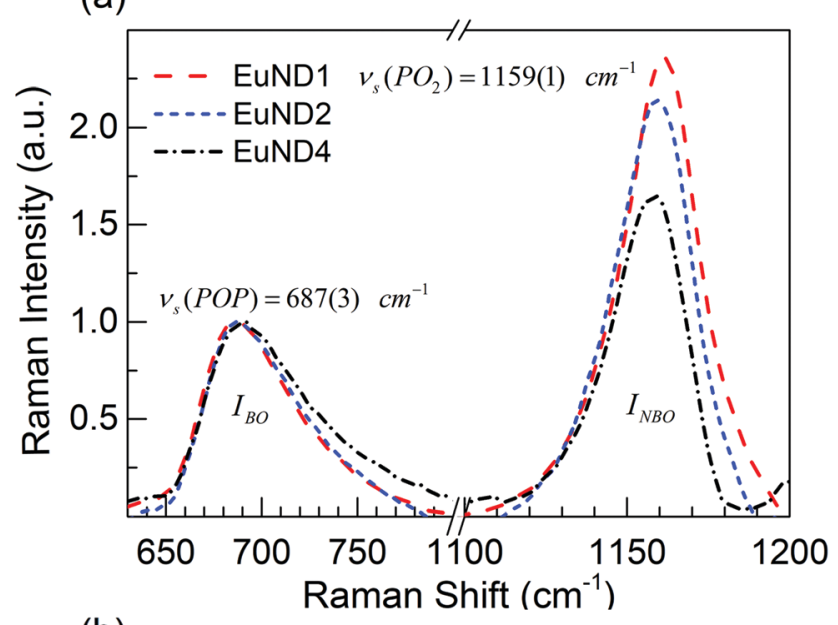

(b)

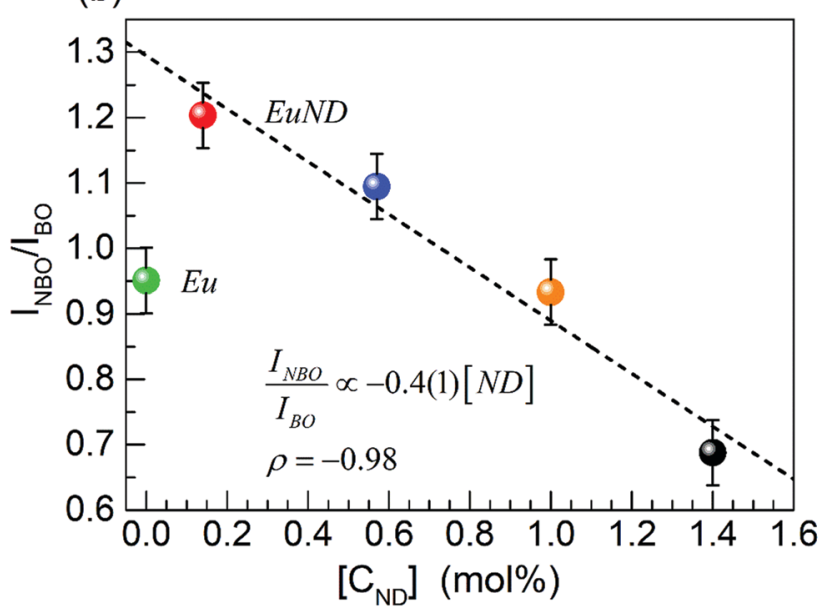

Fig. 7 (a) Raman spectra overlay normalized to the peak of the bridging oxygen $\mathrm{P}-\mathrm{O}-\mathrm{P}$ band; (b) relative Raman band intensity, $I_{\mathrm{NBO}} / /_{\mathrm{BO}}$ as a function of the molar $C_{N D}$ concentration in the melt. The slope of the linear regression and the Pearson's coefficient $\rho$ is listed.

do not yield a detectable new Raman band. However, the $\mathrm{C}_{\mathrm{ND}}$ codoping lessens the number of the NBOs. Furthermore, from the red shift of the high frequency wing of the $\nu_{\mathrm{s}}\left(\mathrm{PO}_{2}\right)$ band, it is apparent that there is a tendency for the $\mathrm{C}_{\mathrm{ND}}$ to bond to NBOs more strongly affected by the electrostatic field of the cations. Thus, according to the most prominent Raman band, $\nu_{\mathrm{s}}\left(\mathrm{PO}_{2}\right)$, the NBO bond distribution in the matrix exhibits a tendency to be symmetrized by the elevated $\mathrm{C}_{\mathrm{ND}}$ doping concentrations. At the same time, the symmetric stretching $\nu_{\mathrm{s}}$ (POP) band position of the EuND4 glass [black dash dot line, Fig. 7(a)] shifts toward higher wavenumbers (stronger bonds) relative to the EuND1 glass. The noticeable integral intensity increase of the Raman BO band of EuND4, indicates the presence of an elevated concentration of BO bonds of $Q^{2}$ species in agreement with ${ }^{31} \mathrm{P}$ NMR..${ }^{9,10}$ Overall, the Raman trends indicate an increased covalent character of the tetrahedral units' bonds. The observations corroborate with the DSC study of the glass transition regime as considered next.

The glass transition range is characterized utilizing a recently proposed new experimental method: the constant cooling rate (CoCR) technique with a novel geometric approach for data analysis. ${ }^{13}$ The CoCR cycles are made possible by acquiring measurement between two thermally equilibrated points: $\sim 50{ }^{\circ} \mathrm{C}$ above and $\sim 50{ }^{\circ} \mathrm{C}$ below the glass transition temperature, $T_{\mathrm{g}}$, thus keeping the cooling rates constant, while varying the heating rates. The thermal history for each sample is established by an initial up and down scan cycle setting $T_{\mathrm{g}}$ to be equal to the fictive glass temperature. The proposed glass transition range geometric analysis includes the algorithmized numerical evaluation of $T_{\mathrm{g}}$, activation energy, $E_{T_{\mathrm{g}}}$, and the liquid fragility parameter, $m$, and their corresponding uncertainties. Fig. 8 summarizes the results for each EuND glass composition. The DSC analysis gives more specific insight on the overall bond strength via experimental evaluation of the activation energy of the glass transition, $E_{T_{\mathrm{g}}}$. The $T_{\mathrm{g}}$ was determined as the inflection point of the heat flow curve, (not shown) at each one of four DSC ramping rates $\left(10{ }^{\circ} \mathrm{C} / \mathrm{min}\right.$, $20{ }^{\circ} \mathrm{C} / \mathrm{min}, 40{ }^{\circ} \mathrm{C} / \mathrm{min}$ and $60{ }^{\circ} \mathrm{C} / \mathrm{min}$ ). Fig. 8 (top panel) summarizes the results for heating rate $10{ }^{\circ} \mathrm{C} / \mathrm{min}$. The measured $T_{\mathrm{g}}$ values show slightly increasing trend with the $\mathrm{C}_{\mathrm{ND}}$ concentration. The confidence interval of the measurand was estimated via a procedure reflecting the broadness of the

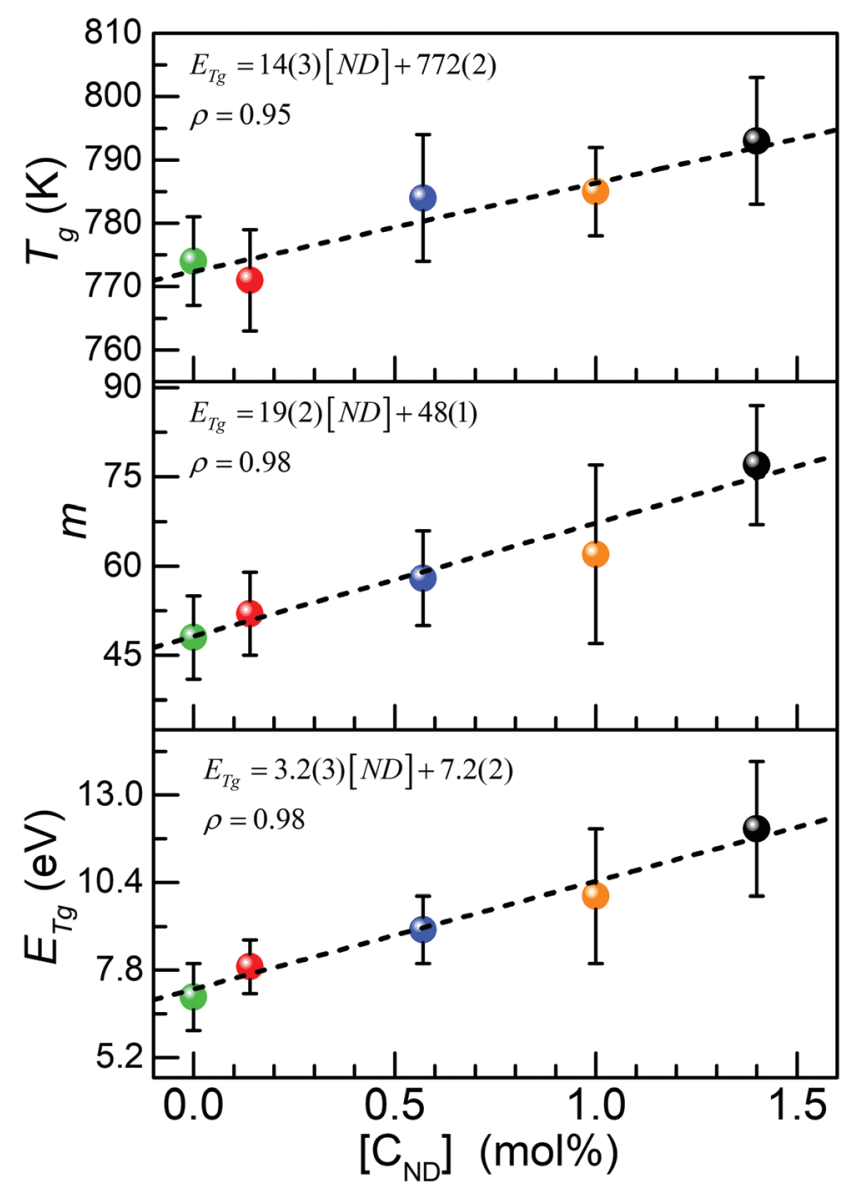

Fig. 8 Glass transition temperature, $T_{\mathrm{g}}$, at $10{ }^{\circ} \mathrm{C} \mathrm{min}^{-1}$ (top), liquid fragility, $m$, (middle) and the glass transition activation energy, $E_{T_{g}}$ (bottom) as a function of the molar $\mathrm{C}_{\mathrm{ND}}$ concentration in the melts. The linear regression and the Pearson's coefficients $\rho$ are listed. The data points at 0 mol\% stand for the Eu reference glass. 


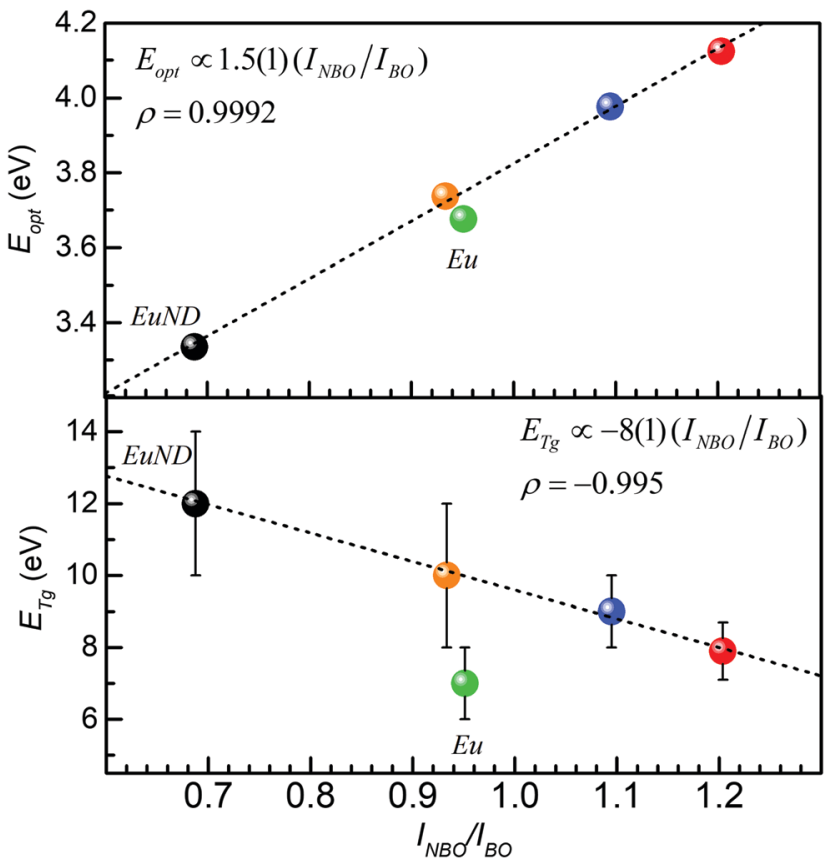

Fig. 9 Optical band gap (top) data and glass transition activation energy (bottom) correlated with the relative Raman $\mathrm{NBO}$ s band intensity, $I_{\mathrm{NBO}} / /_{\mathrm{BO}}$. The linear regression and the Pearson's coefficients $\rho$ are listed. The green data point is the Eu reference glass.

glass transition regime, rather than the accuracy of the mathematical procedure for finding the inflection point. Utilizing the $T_{\mathrm{g}}$ values obtained for each ramping rate and an Arrhenius-type plot $^{28}$ the glass transition activation energy, $E_{T_{\mathrm{g}}}$, of the EuND glasses was determined to be between $7 \mathrm{eV}$ and $11 \mathrm{eV}$ increasing with the $\mathrm{C}_{\mathrm{ND}}$ concentration, Fig. 8 (bottom panel). Similar range of increase, but with much poorer correlation was reported for MWCNT and Eu doped glass. ${ }^{20}$ The $E_{T_{\mathrm{g}}}$ rising trend suggests overall average increase of the covalent nature of glass former, thus increasing the energy threshold for the onset of the $\mathrm{P}-\mathrm{O}$ bond exchange mechanism. The bond exchange mechanism involves $\mathrm{P}-\mathrm{O}$ bond severing for allowing a phosphorus exchange between adjacent tetrahedral units. ${ }^{28}$ Further on, the experimental determination of $T_{\mathrm{g}}$ and $E_{T_{\mathrm{g}}}$ allows for assessing the liquid fragility parameter, $m$, of the carbon-modified host matrix. The liquid fragility, $m$, is a dimensionless phenomenological description of the structural ordering ('strength') of quenched liquids. ${ }^{29}$ To calculate the liquid fragility, $E_{T_{\mathrm{g}}}$ value, in $\mathrm{eV}$ is utilized as well as $T_{\mathrm{g}}$ in $\mathrm{K}$ (at standard $10{ }^{\circ} \mathrm{C}$ per min rate) ${ }^{30}$ by

$$
m=\frac{E_{T_{\mathrm{g}}}}{2.303 R_{\mathrm{G}} T_{\mathrm{g}}}
$$

where $R_{\mathrm{G}}$ is the universal gas constant in $\mathrm{eV} \mathrm{K}^{-1}$. The assessed value of $m$ is between 48 and 77 summarized as a function of the ND mol\% in Fig. 8 (middle panel). The confidence interval is estimated via traditional error propagation from the uncertainty of the variables in eqn (4). Larger liquid fragility values are indicative of less structural ordering due to the increased dissimilarity of the modifier cation sites triggered by the different roles $\mathrm{C}_{\mathrm{ND}}$ plays as a co-dopant.

Finally, Fig. 9 summarizes the synergistic connection between UV-Vis transmission, Raman spectroscopy, and the calorimetric study. The positive correlation of the $E_{\text {opt }}$ to Raman band integral intensity ratio, $I_{\mathrm{NBO}} / I_{\mathrm{BO}}$, suggests the recognizable role the NBO bonds play for the evolution of the $E_{\mathrm{opt}}$. At the same time, the negative correlation presented in the bottom panel, suggests a prevalent contribution of the BO bonds to the glass transition processes (vide supra). The red data points represent EuND1, the orange data point EuND2, the blue data point EuND3, and the black data point the EuND4 glass. Comparing the slopes of the fitted lines one can propose that $E_{T_{\mathrm{g}}}$ is more sensitive $(5.3 \times)$ to the Raman assessed integral structural parameter $I_{\mathrm{NBO}} / I_{\mathrm{BO}} \cdot E_{T_{\mathrm{g}}}$ has slope of $-8 \mathrm{eV}$, compared to $E_{\text {opt }}$ fit line with slope of $1.5 \mathrm{eV}$.

\section{Conclusions}

A series of five co-doped phosphate glasses were melted with fixed $\mathrm{Eu}_{2} \mathrm{O}_{3}$ content and varying amounts of ND powder. Four synergistic techniques: optical transmission, PL spectroscopy, Raman scattering, and calorimetry were applied. A quantitative elucidation of the concentration-related physico-chemical mechanisms of emission spectra and optical band gap evolution in relation to matrix bond structure, suggested from Raman spectroscopy and the DSC analysis was reported. The $\mathrm{C}_{\mathrm{ND}}$ induced structural changes were also previously supported in our group. ${ }^{9,10}$ A novel integral parameter, $\eta$, was proposed for evaluating the PL spectra. Compelling linear correlations were established between the $\mathrm{C}_{\mathrm{ND}}$ concentration and: (1) optical band gap, $E_{\text {opt }}$; (2) PL $\eta$ factor; (3) Raman integral intensity band ratio; (4) glass transition temperature, $T_{\mathrm{g}}$; (5) glass transition activation energy, $E_{T g}$; and (6) liquid fragility factor, $m$. The data were correlated and discussed in the context of energy band theory, and the $\mathrm{C}_{\mathrm{ND}}$ induced bond and cation modifications. The optical band gap was calculated from the transmission spectra via Tauc plots to vary between $4.1 \mathrm{eV}$ and $3.3 \mathrm{eV}$ with $\mathrm{C}_{\mathrm{ND}}$ concentration. The optical band gap values were compared and discussed in relation to the barium phosphate glass without europium doping. The band gap values of the EuND1-4 series of glasses inversely correlate to the $\mathrm{C}_{\mathrm{ND}}$ concentration and are proportional to the integral intensity ratio $I_{\mathrm{NBO}} / I_{\mathrm{BO}}$ of the Raman active bands of the phosphate matrix. The $\mathrm{Eu}^{2+}$ absorption band of $4 \mathrm{f}^{7} \rightarrow$ $4 \mathrm{f}^{6} 5 \mathrm{~d}$ transition was deduced from the absorption spectra and utilized to explain the optical band gap narrowing concentration trend. The novel method for quantifying the photoluminescent spectra suggested was correlated to the $\mathrm{C}_{\mathrm{ND}}$ concentration and to the optical band gap. Further on, DSC was used to corroborate the data with the Raman and optical studies. Emission with broad tunability was achieved due to variation in the $\mathrm{C}_{\mathrm{ND}}$ concentration which may be of interest for material developments toward photonic applications. The $\mathrm{C}_{\mathrm{ND}}$ doping versatility as chemical reductant of $\mathrm{Eu}^{3+}$ ions and as an efficient modifier of the optical properties of the glass matrix appear 
attractive to exploit for future technologies in glass-based photonics.

\section{Author contributions}

Mariana Sendova: conceptualization, visualization, methodology, investigation, formal analysis, writing - original draft, reviewing and editing. José A. Jiménez: conceptualization, visualization, methodology, investigation, formal analysis, writing - original draft, reviewing and editing, supervision.

\section{Conflicts of interest}

The authors declare that they have no known competing financial interests or personal relationships that could have appeared to influence the work reported in this paper.

\section{Acknowledgements}

M. S. thanks undergraduate student M. Mancini for collecting the DSC data.

\section{References}

1 S.-J. Yu, M.-W. Kang, H.-C. Chang, K.-M. Chen and Y.-C. Yu, Bright fluorescent nanodiamonds: no photobleaching and low cytotoxicity, J. Am. Chem. Soc., 2005, 127, 17604.

2 V. N. Mochalin, O. Shenderova, D. Ho and Y. Gogotsi, The properties and applications of nanodiamonds, Nat. Nanotechnol., 2012, 7, 11.

3 B.-M. Chang, H.-H. Lin, L.-J. Su, W.-D. Lin, R.-J. Lin, Y.K. Tzeng, R. T. Lee, Y. C. Lee, A. L. Yu and H.-C. Chang, Highly fluorescent nanodiamonds protein-functionalized for cell labeling and targeting, Adv. Funct. Mater., 2013, 23, 5737.

4 H. Siampour, S. Kumar, V. A. Davydov, L. F. Kulikova, V. N. Agafonov and S. I. Bozhevolnyi, On-chip excitation of single germanium vacancies in nanodiamonds embedded in plasmonic waveguides, Light: Sci. Appl., 2018, 7, 61.

5 M. Radulaski, J. L. Zhang, Y.-K. Tzeng, K. G. Lagoudakis, H. Ishiwata, C. Dory, K. A. Fischer, Y. A. Kelaita, S. Sun, P. C. Maurer, K. Alassaad, G. Ferro, Z.-X. Shen, N. A. Melosh, S. Chu and J. Vučković, Nanodiamond integration with photonic devices, Laser Photonics Rev., 2019, 13, 1800316.

6 S.-R. Qin, Q. Zhao, Z.-G. Cheng, D.-X. Zhang, K.-K. Zhang, L.--X. Su, H.-J. Fan, Y.-H. Wang and C.-X. Shan, Rare earthfunctionalized nanodiamonds for dual-modal imaging and drug delivery, Diam. Relat. Mater., 2019, 91, 173.

7 H.-S. Jung, K.-J. Cho, S.-J. Ryu, Y. Takagi, P. A. Roche and K. C. Neuman, Biocompatible fluorescent nanodiamonds as multifunctional optical probes for latent fingerprint detection, ACS Appl. Mater. Interfaces, 2020, 12, 6641.

8 J.-X. Qin, X.-G. Yang, C.-F. Lv, Y.-Z. Li, K.-K. Liu, J.-H. Zang, X. Yan, L. Dong and C.-X. Shan, Nanodiamonds: Synthesis, properties, and applications in nanomedicine, Mater. Des., 2021, 210, 110091.
9 J. A. Jiménez and M. Sendova, Nanodiamond-induced UV transparency in phosphate glasses and development of plasmonic Cu nanocomposites, J. Non-Cryst. Solids, 2020, 544, 120193.

10 M. Sendova and J. A. Jiménez, Band gap analysis and correlation with glass structure in phosphate glasses melted with various allotropes of carbon, Chem. Phys., 2021, 547, 111207.

11 J. A. Jiménez, M. Sendova, E. R. Fachini and C. Zhao, Enhanced UV transparency in phosphate glasses via multiwall carbon nanotubes, J. Mater. Chem. C, 2016, 4, 9771.

12 J. A. Jiménez, On the graphite-induced UV transparency in phosphate glasses, Opt. Mater., 2016, 62, 42.

13 M. Mancini, M. Sendova and J. C. Mauro, Geometric analysis of the calorimetric glass transition and fragility using constant cooling rate cycles, Int. J. Appl. Glass Sci., 2021, 12, 348 .

14 S. Tomita, A. Burian, J. C. Dore, D. LeBolloch, M. Fujii and S. Hayashi, Diamond nanoparticles to carbon onions transformation: X-ray diffraction studies, Carbon, 2002, 40, 1469.

15 T. Gaebel, C. Bradac, J. Chen, J. M. Say, L. Brown, P. Hemmer and J. R. Rabeau, Size-reduction of nanodiamonds via air oxidation, Diam. Relat. Mater., 2012, 21, 28.

16 Y. Tratsiak, M. Buryi, V. Babin, M. Korjik and E. Trusova, The effect of binary glass composition on the Eu-ions luminescence properties, Opt. Mater., 2019, 94, 356.

17 J. A. Jiménez, Optical properties of $\mathrm{Eu}^{3+}$-doped aluminophosphate glass with a high concentration of silver and tin, J. Inorg. Organomet. Polym., 2017, 27, 372.

18 M. Nogami, T. Yamazaki and Y. Abe, Fluorescence properties of $\mathrm{Eu}^{3+}$ and $\mathrm{Eu}^{2+}$ in $\mathrm{Al}_{2} \mathrm{O}_{3}-\mathrm{SiO}_{2}$ glass, J. Lumin., 1998, 78, 63.

19 X. Liang, Z. Xing, Y. Yang, S. Wang and G. Chen, Luminescence properties of $\mathrm{Eu}^{2+} / \mathrm{Mn}^{2+}$ codoped borophosphate glasses, J. Am. Ceram. Soc., 2011, 94, 849.

20 J. A. Jiménez, M. Sendova and M. Mancini, $\mathrm{Eu}^{2+} / \mathrm{Eu}^{3+}$ activated phosphate glasses synthesized via melting with multiwall carbon nanotubes, Opt. Mater., 2020, 109, 110336.

21 N. Mott and E. Davis, Electronic process in non-crystalline materials, Clarendon Press, Oxford, 2nd edn, 1979.

22 A. Aguado, A. Ayuela, J. M. Lopez, J. A. Alonso, J. F. RivasSilva and M. Berrondo, Calculation of the band gap energy of ionic crystals, Rev. Mex. Fis., 1998, 44, 550.

23 V. Luaña and L. Pueyo, Simulation of ionic crystals: The $a b$ initio perturbed-ion method and application to alkali hydrides and halides, Phys. Rev. B, 1990, 41, 3800.

24 E. Malchukova and B. Boizot, Reduction of $\mathrm{Eu}^{3+}$ to $\mathrm{Eu}^{2+}$ in aluminoborosilicate glasses under ionizing radiation, Mater. Res. Bull., 2010, 45, 1299.

25 J. A. Jiménez, S. Lysenko, H. Liu, E. Fachini and C. R. Cabrera, Investigation of the influence of silver and tin on the luminescence of trivalent europium ions in glass, J. Lumin., 2010, 130, 163.

26 Z. Lian, J. Wang, Y. Lv, S. Wang and Q. Su, The reduction of $\mathrm{Eu}^{3+}$ to $\mathrm{Eu}^{2+}$ in air and luminescence properties of $\mathrm{Eu}^{2+}$ activated $\mathrm{ZnO}-\mathrm{B}_{2} \mathrm{O}_{3}-\mathrm{P}_{2} \mathrm{O}_{5}$ glasses, J. Alloys Compd., 2007, 430, 257. 
27 R. K. Brow, Review: The structure of simple phosphate glasses, J. Non-Cryst. Solids, 2000, 263-264, 1.

28 M. Sendova and J. A. Jiménez, Synergistic thermo-Raman and calorimetric kinetic study of the cation $\left(\mathrm{Ca}^{2+}, \mathrm{Ba}^{2+}\right.$, $\mathrm{Pb}^{2+}$ ) modifier's role in binary metaphosphate glasses, J. Raman Spectrosc., 2018, 49, 1522.
29 J. C. Mauro, M. Blodgett, M. L. Johnson, A. J. Vogt and K. F. Kelton, A structural signature of liquid fragility, Nat. Commun., 2014, 5, 4616.

30 Q. Zheng, Y. Zhang, M. Montazerian, O. Gulbiten, J. C. Mauro, E. D. Zanotto and Y. Yue, Understanding glass through differential scanning calorimetry, Chem. Rev., 2019, 119, 7848. 